\title{
Estudo de propriedades térmicas e mecânicas de compósitos cimentícios produzidos com resíduos da indústria madeireira de Porto Velho
}

\author{
Study of thermal and mechanical properties of \\ cementitious composites produced with \\ residues from Porto Velho timber \\ industry
}

\footnotetext{
${ }^{1}$ Programa de Pós-Graduação em Engenharia Civil, Universidade Federal do Amazonas - Campus Universitário, setor Norte - Av. General Rodrigo Octávio, 6200, Coroado I, CEP: 69080-900, Amazonas, Manaus, Brasil.

${ }^{2}$ Programa de Pós-Graduação em Engenharia Civil, Universidade Federal do Amazonas - Campus Universitário, setor Norte - Av. General Rodrigo Octávio, 6200, Coroado I, CEP: 69080-900, Amazonas, Manaus, Brasil.

e-mail: umberto.ribeiro@hotmail.com,vasconcelos@ufam.edu.br
}

\begin{abstract}
RESUMO
O objetivo principal do trabalho foi avaliar compósitos cimentícios com adição de resíduos da indústria de beneficiamento de madeira para aplicação na construção civil como isolante térmico. A matriz de cimento Portland pozolânico CP IV-32 foi modificada substituindo-se parcialmente o cimento por Metacaulinita $(10 \%)$ e hidróxido de cálcio $\left(\mathrm{Ca}(\mathrm{OH})_{2}\right)(5 \%)$, para controle da pega e compatibilidade com os resíduos. Adicionou-se resíduos em teores de 2,5\%, 5,0\% e 7,5\%, em substituição parcial ao agregado miúdo, comparando-se com uma mistura convencional. Os testes de desempenho térmico foram desenvolvidos através de uma caixa de retenção de calor construída com painéis produzidos com as misturas nos percentuais especificados, sendo medidas as temperaturas interna e externa, simultaneamente, durante 30 minutos. As propriedades físicas, resistência à compressão e flexão a 4 pontos foram desenvolvidas para verificação do desempenho físico e mecânico dos compósitos. Os resultados mostraram redução na densidade e consumo de materiais convencionais, porém a transmissão de calor entre as faces interna e externa dos painéis apresentou valores estatisticamente equivalentes, com coeficiente de variação $\cong 18 \%$, para a configuração analisada. A Metacaulinita e o $\mathrm{Ca}(\mathrm{OH})_{2}$ adicionados mostraram melhorias no desempenho físico-mecânico dos compósitos, principalmente nas primeiras idades.
\end{abstract}

Palavras-chave: Materiais não convencionais. Cimento-madeira. Cimento Portland. Resíduo de madeira. Isolamento térmico.

\begin{abstract}
The main objective of this work was to evaluate cementitious composites with addition of waste from wood processing industry for use in construction as a thermal insulator. A matrix of pozzolanic Portland cement $\mathrm{CP}$ IV-32 was modified by partially replacing the cement with Metacaulinite $(10 \%)$ and calcium hydroxide $\left(\mathrm{Ca}(\mathrm{OH})_{2}\right)(5 \%)$, for setting control and compatibility with residues. Residues of $2.5 \%, 5.0 \%$ and $7.5 \%$ were added in partial replacement to the fine aggregate, compared to a conventional mixture. The thermal performance was developed through a heat retention box constructed with panels produced with mixtures in the specified percentages, being measured internal and external temperatures simultaneously for 30 minutes. The physical properties, compressive strength and 4-point bending were developed to verify the physical and mechanical performance of the components. The results showed a reduction in density and consumption of conventional materials, but the heat transfer between internal and external faces of panels presented statistically equivalent values, with coefficient of variation $\cong 18 \%$, on analysed configuration. Metacaulinite and $\mathrm{Ca}(\mathrm{OH})_{2}$ presented improvements on physico-mechanical performance of composites, especially in the early ages.
\end{abstract}

Keywords: Unconventional materials. Wood-cement. Portland Cement. Waste wood. Thermal insulating. 


\section{INTRODUÇÃO}

O paradigma do desenvolvimento sustentável tem provocado recorrentes estudos em termos de materiais alternativos para a indústria da construção civil. A indústria do cimento contribui com cerca de $5 \%$ das emissões mundiais de $\mathrm{CO}_{2}$, além de consumir elevada quantidade de energia no processo de fabricação, sendo imprescindível o desenvolvimento de alternativas para um processo de produção ecologicamente correto [1]. Torna-se necessário o desenvolvimento de novas tecnologias na adição de materiais e agregados que permitam um consumo otimizado do cimento e consequente redução no seu consumo [2].

O setor industrial de beneficiamento madeireiro na região de Porto Velho, RO, na Amazônia brasileira, mostrou uma geração de refugos de beneficiamento com média de 69,34\%, para algumas espécies, sendo as destinações a esses refugos, principalmente, o desenvolvimento de painéis de madeira reconstituída ou queima direta para geração de energia. Mesmo assim, o desuso chega a $51 \%$ [3].

Quanto ao aproveitamento desses resíduos para adição em compósitos cimentícios, pesquisas relatam a existência de inconsistências físicas e químicas na combinação dos materiais, apresentando alternativas com pré-tratamentos para os resíduos, visando melhorar a compatibilidade entre ambos. Algumas das principais desvantagens nessa mistura são o aumento no tempo de pega do compósito e a redução na força de ligação entre as matérias-primas [4-6].

As incompatibilidades genericamente estão estabelecidas entre dois mecanismos: primeiro, no princípio de que os extrativos compostos por vários componentes orgânicos presentes na madeira provocam um desequilíbrio químico na mistura ao reduzir a concentração dos íons $\mathrm{Ca}^{2+}$, retardando o início da formação de compostos essenciais do compósito endurecido. Segundo, pelo fato de que os compostos orgânicos formam uma fina camada na superfície dos grãos de cimento, tornando lento o processo de hidratação [4].

Assim, várias técnicas são empregadas para melhorar o desempenho do compósito: lavagem dos resíduos em água fria e/ou quente, utilização de soluções de aditivos químicos aceleradores de pega, e até injeção de $\mathrm{CO}_{2}$. O método de carbonatação da mistura promete, já nos primeiros minutos, uma aceleração na formação dos produtos da hidratação (carbonato de cálcio e silicato de cálcio), promovendo um rápido endurecimento da mistura [4]. Estudos que avaliaram a eficácia de tratamentos realizados com soluções de água, $\mathrm{CaCl}_{2}$ (cloreto de cálcio), $\mathrm{MeOH}$ (metanol) e $\mathrm{Ca}(\mathrm{OH})_{2}$ (hidróxido de cálcio), mostraram que o melhor desempenho foi obtido com este último [5].

Embora o emprego do $\mathrm{Ca}(\mathrm{OH})_{2}$ em testes de compatibilidade possa apresentar resultados divergentes, o composto, utilizado como pré-tratamento, foi o que apresentou melhores resultados de resistência à compressão axial nos compósitos cimento-madeira estudados por CASTRO et al [7]. Além disso, o emprego de aditivos, a adequação do fator água/cimento e a escolha do tipo certo de cimento melhoram significativamente a compatibilidade do compósito $[8,9]$.

Procurando contornar o atraso na hidratação do cimento, MEDINA [10] relata que a adição de metacaulim aos compósitos cimentícios provoca uma aceleração no processo de hidratação e favorece o efeito fíler, ideais ao ganho de resistência no primeiro dia, e melhora o ganho de resistência pela atividade pozolânica do sétimo ao décimo quarto dia. Esta reação é potencializada pela adição de pequenas porções de $\mathrm{Ca}(\mathrm{OH})_{2}$.

Por outro lado, o produto madeireiro adicionado a argamassas de cimento Portland provoca queda no desempenho mecânico à compressão, influenciado por fatores como tamanho da partícula, índice de vazios, taxa de absorção de água e densidade do compósito, entre outros [11].

Assim, a necessidade do desenvolvimento de materiais cimentícios de baixa densidade e um bom desempenho mecânico vai ao encontro do aproveitamento dos resíduos da indústria madeireira, levando-se em conta ainda, aspectos positivos como isolamento térmico e acústico, redução dos custos, impacto ambiental, resistência ao fogo, etc. [12]. Além disso, a fabricação de compósitos de cimento-madeira é um processo que não gera resíduos tóxicos, não requer pré-tratamentos de conservação e tem um baixo consumo de energia [13].

A porosidade do produto madeireiro é um dos fatores que beneficiam as propriedades térmicas de placas de cimento-madeira, uma vez que estas possuem baixa condutividade térmica e podem contribuir para reduzir a transmissão de calor em paredes, chegando a ter condutividade térmica cerca de três vezes menor do que as fabricadas com gesso, por exemplo [9].

Desse modo, buscou-se estudar o desempenho térmico e mecânico de compósitos cimento-madeira produzidos com resíduos da indústria madeireira da região de Porto Velho, com a finalidade de aplicação na construção civil como isolante térmico. 


\section{MATERIAIS E MÉTODOS}

\subsection{Caracterização dos materiais}

\subsubsection{Cimento Portland}

O cimento Portland escolhido foi o CP IV-32 [14], adquirido no comércio de Porto Velho, produzido na Empresa Votorantim Cimentos - Unidade Porto Velho.

Para a caraterização do cimento foi realizado o procedimento de peneiramento descrito na NBR 11579 [15], utilizando a peneira $75 \mu \mathrm{m}$, para que fosse possível determinar o módulo de finura (F) pela equação:.

$$
F=(R x C / M) x 100
$$

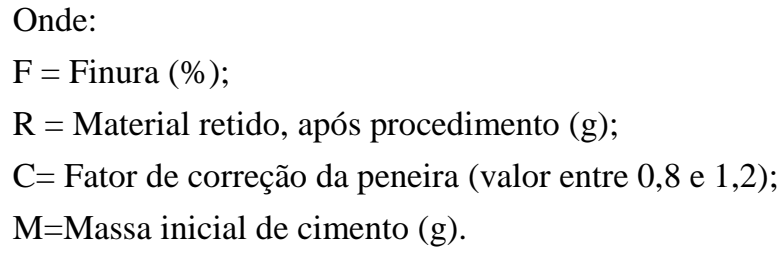

Quanto à determinação dos tempos de início e fim de pega, foram feitos os procedimentos descritos na NBR NM 65 [16], através do procedimento utilizando o aparelho de Vicat para perfuração de uma pasta cimentícia padronizada, em tempos sucessivos, e a respectiva capacidade de penetração. A verificação dos tempos de hidratação inicial e endurecimento da pasta determinaram os tempos de pega.

Para avaliação da composição química do cimento foi empregado o ensaio de fluorescência de raios-X, para tanto, foi empregado o equipamento Epsilon XL, marca Panalytical.

\subsubsection{Resíduos de madeiras}

Os resíduos de madeira foram coletados na indústria de beneficiamento de madeira em toras, denominada Serraria Isabela (Candeias do Jamari - RO), a $18 \mathrm{~km}$ de Porto Velho (Latitude $8^{\circ} 48^{\prime} 9.64$ "S Longitude $\left.63^{\circ} 44^{\prime} 24.97^{\prime \prime O}\right)$ e 4,5 km do município de Candeias do Jamary. A coleta foi feita introduzindo-se uma pá de bico em pilhas pequenas, de aproximadamente $1 \mathrm{~m}^{3}$, formadas junto às máquinas de beneficiamento (serrasfitas, plainas, etc.), optando-se em coletar porções de várias pilhas, para melhor representatividade da amostra (NBR 10007 [17]).

Durante a coleta observou-se o acúmulo de resíduos há, aproximadamente, dois ou três dias, o que pressupõe que nesse período foram processadas várias espécies florestais e, portanto, são resíduos mistos, sendo mais comuns as espécies cedro (Cedrela fissilis), maracatiara (Astronium lecointei) e cerejeira (Amburana Caerensis), conforme informação prestada pelo corpo técnico da empresa.

Após coletados, foram removidos manualmente os refugos diferentes de grânulos, lascas, pó e serragem em geral, pois assim poderiam ser submetidos à classificação através de peneiramento. Os resíduos foram deixados ao ar por $24 \mathrm{~h}$ para estabilização da umidade superficial, em local coberto. Logo após, foram separados $15 \mathrm{~kg}$ desses resíduos e acondicionados em sacos plásticos, amarrados para que não voltassem a absorver umidade e encaminhado ao laboratório de solos da Faculdade de Rondônia - FARO para análise granulométrica, seguindo o mesmo método do agregado mineral (peneiramento), na ausência de normativa específica para os resíduos ([18] e [19]). Para isso utilizou-se um conjunto de peneiras com abertura das malhas (mm) $19 ; 9,5 ; 6,3 ; 4,75 ; 2 ; 1,18 ; 0,6 ; 0,4$ e fundo.

Os resíduos utilizados nos experimentos foram os grãos passantes na peneira $1,18 \mathrm{~mm}$ e retidos na peneira 0,6 mm. Observe-se que os finos passantes na peneira 0,6 $\mathrm{mm}$ foram descartados.

Devido ao fato de serem resíduos mistos, foram coletados também alguns refugos de maiores dimensões, com características físicas diferentes, formatos prismáticos, para posterior análise de densidade e umidade. A massa específica dos resíduos foi obtida a partir da determinação da densidade básica de três amostras de refugos sólidos submetidos ao procedimento padronizado na NBR 7190 [20], procedendo-se o cálculo do quociente da massa seca (em estufa a $103^{\circ} \mathrm{C}$ por $24 \mathrm{~h}$ ) pelo volume saturado (imerso em água por $24 \mathrm{~h}$ ). 


\subsubsection{Agregado miúdo}

O agregado miúdo selecionado para os ensaios foi coletado no areal Areia Branca, confluência dos Rio Candeias e Rio das Garças (Latitude 0849'45.8"S Longitude 06344'32.9"O), a 21 km de Porto Velho e 7,5 km de Candeias do Jamary.

Após a coleta o agregado foi acondicionado em baldes plásticos e tampado, para que fossem preservadas as condições em que foram encontrados.

O material foi coletado em quantidade de, aproximadamente, $60 \mathrm{~kg}$, encaminhando-se cerca de $15 \mathrm{~kg}$ para o laboratório de solos da FARO - Faculdade de Rondônia, para análise granulométrica ([18] e [19]).

Além da granulometria foram verificadas as características DMC (Dimensão Máxima Característica), módulo de finura e teor de umidade do agregado.

Para determinação da umidade foram feitos os procedimentos descritos na DNER-ME 080 [21] e calculada a umidade através da equação:

$$
h=((P h-P s) / P s) \times 100
$$

$$
\begin{aligned}
& \text { Onde: } \\
& h=\text { Umidade }(\%) \\
& P_{h}=\text { Peso do material úmido }(\mathrm{g}) \\
& P_{s}=\text { Peso do material seco }(\mathrm{g})
\end{aligned}
$$

\subsubsection{Metacaulinita, Hidróxido de Cálcio $\left(\mathrm{Ca}(\mathrm{OH})_{2}\right)$ e Aditivo plastificante}

A metacaulinita utilizada neste estudo tem sua origem nos solos argilosos no município de Itacoatiara-AM, sendo produzida nos laboratórios da UFAM - Universidade Federal do Amazonas. Para tanto, o material argiloso passou pelos procedimentos de coleta, secagem $\left(100^{\circ} \mathrm{C} / 24\right.$ horas $)$, destorroamento e moagem. Após a moagem, passou-se o material na peneira $0,075 \mathrm{~mm}$ (mesh 200$)$ e levado ao forno mufla por $3 \mathrm{~h}\left(750^{\circ} \mathrm{C}\right)$ [22].

$\mathrm{O} \mathrm{Ca}(\mathrm{OH})_{2}$ foi adquirido no comércio de Porto Velho e submetido a análise de densidade pelo método descrito na NBR NM 23 [23]. Este procedimento foi utilizado por ser também adequado para materiais finos semelhantes ao cimento. O líquido de imersão utilizado foi o querosene colocado no frasco de Chatelier, aonde foram imersos $60 \mathrm{~g}$ do material e feitas as leituras no corpo graduado do recipiente.

O aditivo plastificante utilizado foi o MasterPolyheed $® 30$ produzido pela BASF SA, inerte quanto ao tempo de pega do cimento, com base química em lignosulfonatos (melhora a coesão e diminui a segregação), aplicável para melhorar trabalhabilidade de compósitos cimentícios, com densidade entre 1,15 e $1,19\left(\mathrm{~g} / \mathrm{cm}^{3}\right)$ [24], fornecido pela Empresa Supermix - Unidade Porto Velho. O plastificante foi utilizado para permitir a redução do fator água/cimento.

\subsection{Procedimentos experimentais}

\subsubsection{Produção do compósito cimento-madeira}

Os resíduos selecionados por peneiramento (vide 2.1.2) foram imersos em água por 24 horas e depois escorridos, para que adquirissem o estado saturado superfície seca. Para isso foram deixados secar ao ar, por 3 horas, depois de escorridos.

A areia foi peneirada e utilizada a fração passante na peneira $1,18 \mathrm{~mm}$. Como a areia era lavada de rio foram utilizados também os finos abaixo do diâmetro selecionado, sem quaisquer tratamentos adicionais.

Uma vez que o fator água/cimento é um dos pontos críticos no desempenho dos compósitos cimentomadeira e, considerando o teor ótimo de água de amassamento para estes compósitos variando no intervalo de 0,30 a 0,45 [8], adotou-se neste estudo o índice de 0,40. Deve-se salientar que os índices próximos de 0,30 são considerados impraticáveis, pois a mistura fica muito seca e de difícil amassamento, conforme foi observado por testes realizados durante o desenvolvimento da pesquisa.

Para execução das misturas partiu-se da relação cimento-areia em 1:3 [25], para o traço T1, substituindo-se o agregado miúdo em frações percentuais, relativas à sua massa, em 2,5\%,5,0\% e 7,5\% pelo resíduo de madeira nos traços $\mathrm{T} 2$, $\mathrm{T} 3$ e T4, respectivamente. O teor de $0 \%$ serviu como referência para a determinação dos demais índices de substituição pelos resíduos. A Tabela 1 mostra a definição dos traços para a 
produção do compósito.

Tabela 1: Definição dos traços para a produção dos compósitos. *aglomerantes. **agregados

\begin{tabular}{c|l|l|l}
\hline TRAÇO & TEOR [cimento:metacaulinita:cal] $]^{\star}:[a r e i a: r e s i ́ d u o]^{\star *}$ & DESCRIÇÃO & $\begin{array}{l}\text { CONSUMO DE } \\
\text { CIMENTO } \\
\mathbf{( k g / m 3 )}\end{array}$ \\
\hline T1 & {$[1: 0: 0]:[3: 0]$} & Referência-1 & 534,13 \\
\hline T2 & {$[0,85: 0,1: 0,05]:[2,925: 0,075]$} & $2,5 \%$ resíduo & 504,95 \\
\hline T3 & {$[0,85: 0,1: 0,05]:[2,850: 0,150]$} & $5,0 \%$ resíduo & 485,53 \\
\hline T4 & {$[0,85: 0,1: 0,05]:[2,775: 0,225]$} & $7,5 \%$ resíduo & 463,35 \\
\hline T5 & {$[0,85: 0,1: 0,05]:[3: 0]$} & Referência-2 & 531,40 \\
\hline
\end{tabular}

A fração unitária de cimento, por sua vez foi reduzida substituindo-se 0,1 parte (10\%) por metacaulinita e 0,05 parte $(5 \%)$ por $\mathrm{Ca}(\mathrm{OH})_{2}$ (cal hidratada).

Uma vez que a atividade pozolânica da metacaulinita está relacionada à superfície específica nas primeiras idades de hidratação do cimento e no ganho de resistência [22] e que nesta fase o componente madeireiro mostra sua incompatibilidade, optou-se por adicionar $10 \%$ da metacaulinita e $5 \%$ de $\mathrm{Ca}(\mathrm{OH})_{2}$, em substituição a igual teor do cimento, visando potencializar o ganho de resistência nas idades iniciais.

O traço T5 foi desenvolvido para verificar a influência dos resíduos nos resultados de desempenho mecânico do compósito (resistência a compressão).

A trabalhabilidade da mistura foi melhorada com a adição do plastificante MasterPolyheed® 30 no teor de $1 \%$ relativo à massa do cimento, conforme indicação do fabricante [24].

\subsubsection{Produção dos painéis}

Para a produção dos painéis foi preparada uma forma metálica com capacidade de fabricação para 5 peças por vez, nas dimensões especificadas $(500 \times 500 \times 15 \mathrm{~mm})$, com o intuito de obter as 4 faces laterais da caixa para os ensaios térmicos, além de uma peça adicional como garantia contra quebras acidentais, e também para que todas os painéis, em cada teor de resíduo, possuíssem as mesmas características em termos de produção (temperatura e umidade ambientais, idade, etc).

Para o traço T1 foram produzidas misturas com os seguintes quantitativos de materiais: $2000 \mathrm{~g}$ de cimento, $6000 \mathrm{~g}$ de areia, $800 \mathrm{~g}$ de água. Separou-se a areia peneirada, à qual foram adicionados os demais materiais na sequência:

1. $50 \%$ do cimento e mistura até homogeneização

2. $50 \%$ da água e mistura até homogeneização

3. restante do cimento e mistura até homogeneização

4. restante da água + plastificante e mistura até homogeneização.

Estas quantidades foram verificadas como suficientes para enchimento e moldagem de cada painel, sendo executada uma mistura manual para cada unidade. No traço T1 não foi adicionado o aditivo plastificante.

As quantidades de materiais dosadas para este procedimento serviram de base para moldagem dos demais painéis com adição dos resíduos, adicionando-se $1 \%$ (20g, relativo à massa do cimento) do plastificante à segunda parte da água de amassamento.

A forma metálica foi previamente envolvida com fina camada de óleo mineral (visando facilitar a desmoldagem), colocada sobre um substrato plano, forrado com a embalagem de papel do cimento, o qual foi pincelado levemente com água (para evitar que viesse a absorver parte da água da mistura). Após completa homogeneização (cerca de 10 minutos) a mistura foi lançada e feita a compactação e nivelamento através de régua metálica.

A desmoldagem dos painéis foi feita após 24 horas com a remoção da forma metálica, efetuando-se levemente algumas batidas para facilitar o descolamento, e deixados por mais 48 horas até sua remoção do local. Nesse período e até que se completassem sete dias, os painéis, com e sem resíduos, foram aspergidos diariamente com água limpa para manter a cura úmida.

Os painéis foram armazenados à sombra até que se completassem os 28 dias relativos ao processo de 
cura e endurecimento iniciais, antes de quaisquer testes de desempenho.

\subsubsection{Desempenho térmico}

O método de avaliação do desempenho térmico (taxa de absorção de calor) foi adaptado de ADRIAZOLA [26], através da construção de um dispositivo composto por um conjunto de painéis, fechados em uma caixa formando um cubo (Figura 1). Embora no modelo de ADRIAZOLA [26] os ensaios foram realizados em ambiente externo, neste estudo foram reduzidas pela metade as dimensões do dispositivo e realizados os ensaios em laboratório, com a fonte de calor inserida no interior da caixa, construída com o material em estudo.

A construção do dispositivo foi efetuada fazendo-se uma colagem dos painéis por suas bordas, conforme o teor dos resíduos adicionados, utilizando-se uma pasta cimentícia idêntica à matriz aglomerante dos painéis e encaixando-os na base e tampa do dispositivo (Figura 2(a)).

A fonte calorífica inserida na caixa foi composta por duas lâmpadas mistas de mercúrio de alta pressão com potência total de 320 Watts (Figura 2(b)). As características das lâmpadas estão descritas na Tabela 2 .

Foram efetuadas medições de temperatura interna e externa, durante 30 min em intervalos de 6 minutos após iniciada a emissão de calor (Figura 2(c)), ou até que a temperatura na face interna da caixa alcançasse $80^{\circ} \mathrm{C}$ (temperatura limite para avaliação de sistemas de vedação verticais expostos a ação de calor [27]).

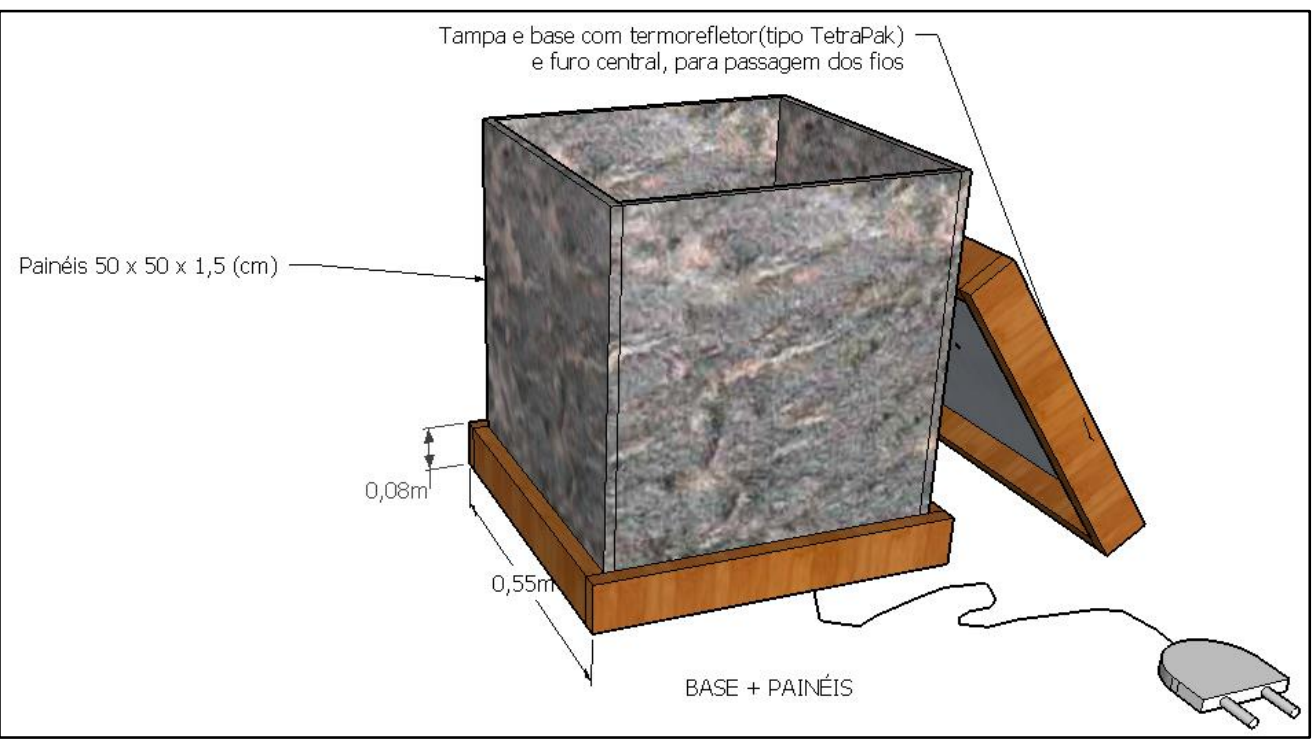

Figura 1: Dispositivo para ensaios de desempenho térmico.

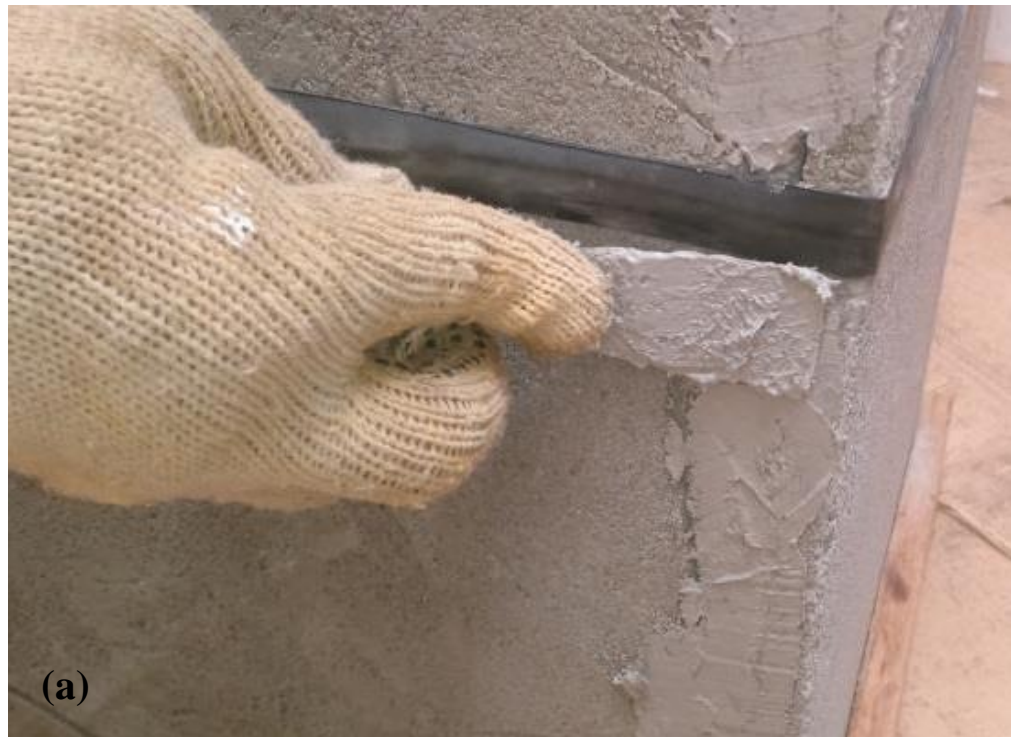



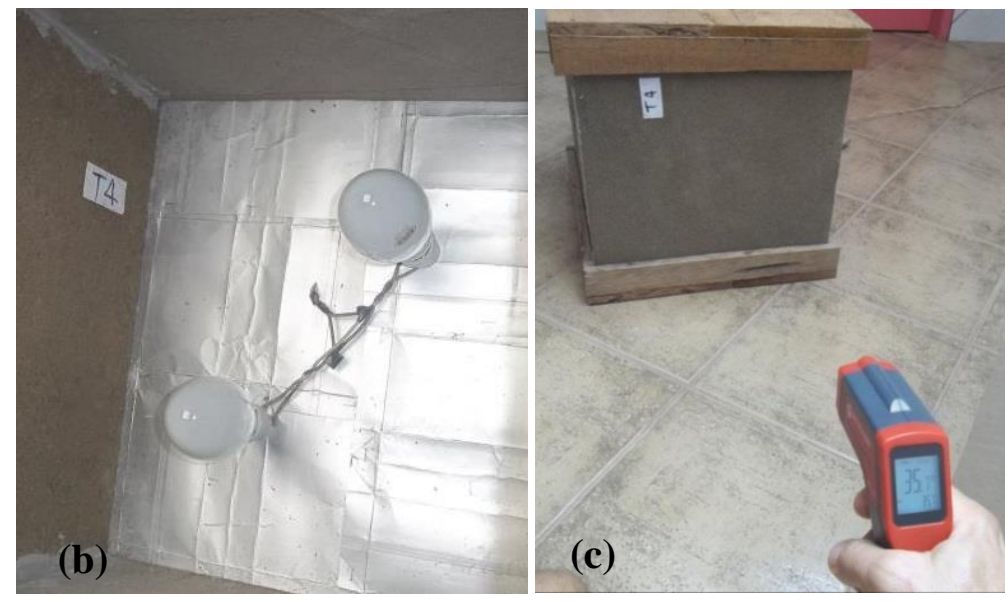

Figura 2: Colagem dos painéis (a). Montagem das lâmpadas (b) e medição da temperatura externa (c).

Tabela 2: Características da fonte de calor.

\begin{tabular}{l|l}
\hline Fluxo luminoso & $3150 \mathrm{~lm}$ \\
\hline Eficiência luminosa & $20 \mathrm{~lm} / \mathrm{W}$ \\
\hline Temperatura da cor & $3500 \mathrm{~K}$ \\
\hline Vida mediana & $10000 \mathrm{~h}$ \\
\hline Temp. máxima da base & $200^{\circ} \mathrm{C}$ \\
\hline Temp. máxima do Bulbo & $350^{\circ} \mathrm{C}$ \\
\hline
\end{tabular}

Antes de iniciada a emissão de calor foi aferida a temperatura ambiente para referência quanto ao desempenho do material, a qual estava em torno de $30^{\circ} \mathrm{C}$.

Para aferição da temperatura dos painéis foram utilizados dois termômetros: um deles tipo agulha, com precisão de $0,1^{\circ} \mathrm{C}$ e capacidade de medição da temperatura do ambiente e de superfícies por contato até $+230^{\circ} \mathrm{C}$, e o outro do tipo pistola de infravermelho com mira a laser classe II, com capacidade de medição de superfícies sem contato, de $-32{ }^{\circ} \mathrm{C}$ até $+380^{\circ} \mathrm{C}$ e resolução de $0,1^{\circ} \mathrm{C}$.

A leitura da temperatura interna foi efetuada através da verificação do painel indicador do termômetro agulha, inserido através do furo existente na tampa do dispositivo. A haste deste aparelho possui $127 \mathrm{~mm}$ de comprimento, o que permite o seu posicionamento bem próximo ao centro, no espaço interno. A temperatura interna foi determinada em uma única medição a cada $6 \min$ (no tempo $=0$ min, inclusive), em até 30 minutos.

Simultaneamente à medição interna, foi executada em cada face externa, a verificação da temperatura, sendo processado o valor médio das 4 faces para cada painel, num total de 24 medições por tipo de painel (traço da série "T"). Após as medições, o dispositivo era desmontado e remontado com outro tipo de painel, para nova série de medições.

\subsubsection{Desempenho mecânico}

Para a avaliação do desempenho mecânico do compósito foram desenvolvidos os ensaios de compressão axial de corpos de prova cilíndricos, para verificação da resistência a compressão, e flexão de corpos de prova prismáticos a quatro pontos, para verificação do módulo de ruptura (MOR) e módulo de elasticidade (MOE).

Para a resistência a compressão foram moldados corpos de prova cilíndricos com as composições dos traços T1 a T5, utilizando-se um conjunto de formas de PVC. Como estes moldes possuíam diâmetros internos menores em $3 \mathrm{~mm}$ com relação ao recomendado pela NBR $5739(50 \mathrm{~mm})$ [28], as resistências alcançadas foram recalculadas para ajuste às dimensões cilíndricas de $100 \mathrm{~mm}$ x $47 \mathrm{~mm}$, através da equação:

$$
f_{c}=\frac{4 F}{\pi D^{2}}
$$

Onde, 
$f_{c}$ é a resistência à compressão $(\mathrm{MPa})$;

$F$ é a força máxima alcançada $(\mathrm{N})$;

$D$ é o diâmetro do corpo de prova (mm).

Para cada teor de resíduo madeireiro participante na mistura foram moldados 10 corpos de prova, perfazendo 40 amostras. Adicionalmente, mais um conjunto de 10 amostras (T5) foi moldado para verificação da influência do produto madeireiro na resistência à compressão e na massa específica do compósito, num total de 5 amostras com 10 corpos de prova.

Após a desmoldagem (24 horas) dos corpos de prova, estes foram armazenados e submetidos a cura úmida através de banhos de imersão diários por cinco minutos, até o $27^{\circ}$ dia.

Os ensaios de compressão foram realizados aos 28 dias no laboratório de ensaios mecânicos da Votorantim Cimentos - Unidade Porto Velho, após capeamento das amostras com enxofre para regularização das superfícies de contato com a prensa hidráulica. A máquina utilizada foi uma prensa Toni Technik, com capacidade de carga até $300 \mathrm{kN}$, configurada para aplicação de carga a uma velocidade constante de 0,25 Mpa/s.

O ensaio de flexão a quatro pontos foi desenvolvido a partir da preparação de chapas do compósito cimento-madeira nos traços já especificados neste trabalho. Para isto confeccionou-se as chapas nas dimensões de 400 × 100 × 15 mm, sendo em número de 10 corpos de prova, apenas para o teor de adição de resíduos que melhor desempenho apresentou nos ensaios de compressão. Neste caso, foi selecionado o traço T2, conforme desempenho apresentado.

As amostras para os ensaios de flexão passaram pelo processo de cura semelhante aos espécimes utilizados para a compressão, até os 28 dias, quando então foram encaminhados ao Laboratório de Ensaios Mecânicos da Universidade Federal do Amazonas - UFAM para os testes. O conjunto foi então preparado conforme a NBR 12142 [29], marcados os afastamentos dos cutelos de apoio para a borda longitudinal da chapa em $50 \mathrm{~mm}$ e entre esses em três medidas de $100 \mathrm{~mm}$.

Para os ensaios utilizou-se uma máquina de ensaios universal Emic DL30000 com capacidade de carga de até $300 \mathrm{kN}$. Os corpos de prova foram marcados por seus terços a partir dos apoios laterais, sendo então ajustados os cutelos de aplicação de cargas. Os ensaios foram realizados a uma velocidade de carregamento constante de $0,5 \mathrm{~mm} / \mathrm{min}$.

Os resultados foram processados de acordo com as seguintes expressões [29]:

$$
F_{c t m}=\frac{P L}{B D^{2}}
$$

Onde,

$F_{c t m}=$ resistência à flexão a 4 pontos, em Megapascals (MPa).

$P=$ carga máxima aplicadas, em Newton $(\mathrm{N})$.

$L=$ distância entre cutelos de suporte, em milímetros ( $\mathrm{mm})$.

$B=$ largura média do corpo de prova na seção de ruptura, em milímetros (mm).

$D=$ altura média do corpo de prova na seção de ruptura, em milímetros (mm).

$$
f_{c t m}=\frac{3 p a}{b d^{2}}
$$

Onde,

$\mathrm{a}=$ distância média entre a linha de ruptura na face tracionada e a linha correspondente ao apoio mais próximo, em milímetros $(\mathrm{mm})$.

A Equação (4) foi utilizada nos casos onde a ruptura dos corpos de prova ocorreu nos limites terço médio. A Equação (5) para os três casos de ruptura fora do terço médio, na direção dos cutelos de apoio.

Depois de realizados os ensaios de resistência à flexão, foram analisados os Módulos de Ruptura (MOR) e Módulo de Elasticidade (MOE) utilizando-se as Equações (6) e (7), os quais estão demonstrados na Tabela 9.

$$
M O R=\frac{P_{\max } L_{v}}{b h^{2}}
$$


Onde,

Pmax - Força máxima aplicada no corpo-de-prova $(\mathrm{N})$

$L_{v}$ - Distância entre os apoios inferiores $(\mathrm{mm})$

$b$ - Largura do corpo-de-prova (mm)

$h$ - Espessura do corpo-de-prova ( $\mathrm{mm})$

$$
M O E=\frac{F L^{3}}{48 f I}
$$

Onde,

$F$ - Força máxima aplicada no corpo-de-prova $(\mathrm{N})$

$f$ - Flecha máxima

$I$ - Momento de Inércia

$L$ - Comprimento do corpo de prova (mm)

O Momento de Inércia (I) foi calculado pela Equação (8), de acordo com a largura $(b)$ e altura $(h)$ da seção transversal do corpo de prova.

$$
I=\frac{b h^{3}}{12}
$$

\subsection{5 Índices físicos}

Os ensaios para caracterização física foram realizados no Laboratório de Materiais da FARO - Faculdade de Rondônia, com base na NBR 9778 [30]. Os corpos de prova cilíndricos utilizados foram os mesmos moldados para os ensaios de compressão axial, com dimensões de $47 \mathrm{~mm}$ x $100 \mathrm{~mm}$. Para as avaliações físicas foram separados dois espécimes de cada traço estudado (T1 a T5), na quantidade total de 10 corpos de prova, visando levantar os dados em duplicata, e obtenção de um valor médio para as medições. O método utilizado foi a sequência de determinações dos índices por imersão dos corpos de prova em água limpa.

Os corpos de prova passaram por processos de secagem em estufa a $110^{\circ} \mathrm{C}$, pesagem a seco, saturação em água, pesagem hidrostática e pesagem saturada com superfície seca, registrando-se todas as massas em cada pesagem.

\section{RESULTADOS E DISCUSSÃO}

\subsection{Análise das características dos materiais}

O cimento Portland CP IV-32, analisado e utilizado neste estudo, mostrou uma composição química (Tabela 3) compatível com as especificações da NBR 5736 [14].

Os componentes silicoaluminosos $\left(\mathrm{Al}_{2} \mathrm{O}_{3}+\mathrm{SiO}_{2}\right)$, característicos do material pozolânico, participam com cerca de $47 \%$ na composição, não excedendo os valores normativos especificados entre 15-50\%. O Óxido de magnésio $(\mathrm{MgO})$ encontrado foi em percentual mínimo, dentro do limite exigido pela norma (até $6,5 \%)$.

$\mathrm{O}$ anidrido sulfúrico $\left(\mathrm{SO}_{3}\right)$, embora levemente acima do limite normativo de 4\%, não chegou a afetar os parâmetros de tempos de início e fim de pega, comprovados em 170 min e 380 min (limites normativos entre 60 e 720 minutos, respectivamente).

Quanto à finura do cimento analisado foi verificada em $6,7 \%$, abaixo de $8 \%$ padronizados para este tipo de cimento. 
Tabela 3: Composição química do CP IV-32 analisado.

\begin{tabular}{c|r}
\hline ÓXIDOS & \multicolumn{1}{|c}{ COMPOSIçÃo (\%) } \\
\hline $\mathrm{MgO}$ & 1,59 \\
\hline $\mathrm{Al}_{2} \mathrm{O}_{3}$ & 11,35 \\
\hline $\mathrm{SiO}_{2}$ & 35,63 \\
\hline $\mathrm{P}_{2} \mathrm{O}_{5}$ & 0,34 \\
\hline $\mathrm{SO}_{3}$ & 4,60 \\
\hline $\mathrm{K}_{2} \mathrm{O}$ & 0,57 \\
\hline $\mathrm{CaO}$ & 40,50 \\
\hline $\mathrm{TiO}_{2}$ & 1,03 \\
\hline $\mathrm{V}_{2} \mathrm{O}_{5}$ & 0,03 \\
\hline $\mathrm{Cr}_{2} \mathrm{O}_{3}$ & 0,02 \\
\hline $\mathrm{MnO}$ & 0,03 \\
\hline $\mathrm{Fe}_{2} \mathrm{O}_{3}$ & 3,40 \\
\hline $\mathrm{ZnO}$ & 0,02 \\
\hline
\end{tabular}

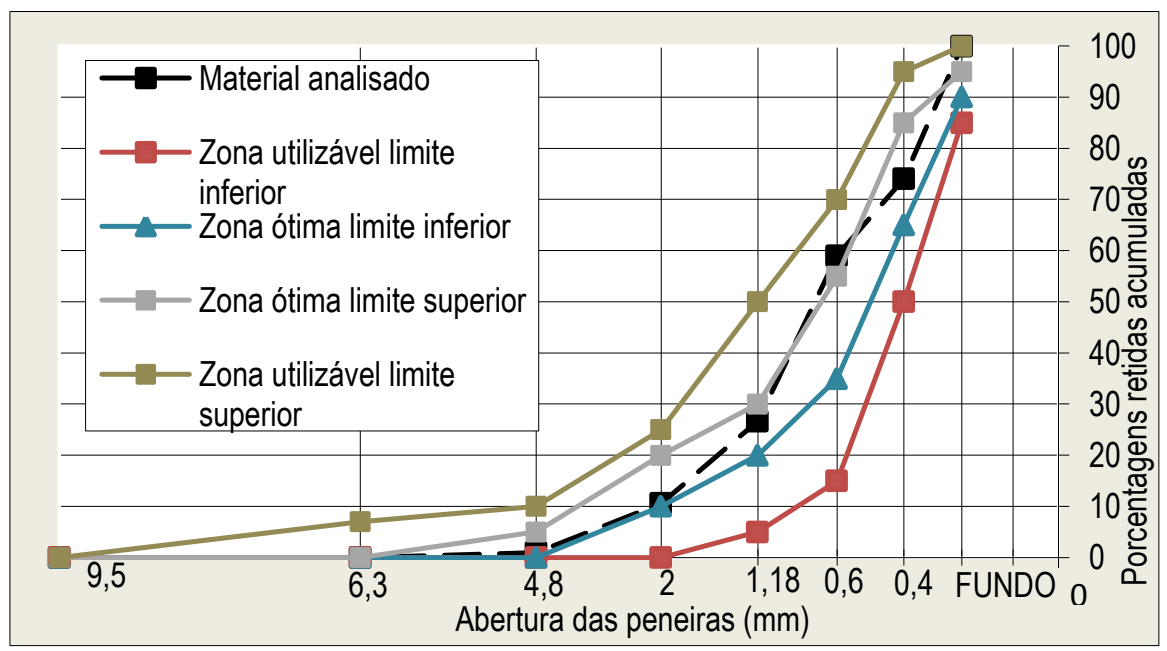

Figura 3: Granulometria da areia, com referência às zonas ótimas e utilizáveis, conforme NBR 7211 e NBR 7217 ([18] e [19]).

O resultado da análise granulométrica do agregado miúdo coletado para o compósito está representado no gráfico da Figura 3. Comparando-se a faixa granulométrica do material em estudo com as determinações da norma, observa-se que a mesma se situa em intervalo médio em conformidade com os padrões, na faixa ótima de utilização. A faixa de grãos selecionados para este estudo, incluídos os finos, essenciais no preenchimento dos espaços entre grãos, favorece a compacidade do compósito e auxilia na redução dos vazios. O módulo de finura para o agregado apresentou índice de 2,71 [18]. A umidade natural da areia determinada foi de $2,52 \%$.

A análise granulométrica dos resíduos, considerando o material na forma como coletado, a partir do diâmetro característico em 19 mm, apresentou os índices apresentados na Tabela 4 e Figura 6. Encontra-se representado também na Figura 6 a faixa granulométrica selecionada para o compósito em estudo, qual seja, os grãos passantes na peneira $1,18 \mathrm{~mm}$ e retidos na peneira $0,6 \mathrm{~mm}$. 
Tabela 4: Granulometria e umidade dos resíduos ([18] e [19]).

\begin{tabular}{l|r}
\hline \multicolumn{1}{c|}{ CARACTERÍSTICAS DOS RESÍDUOS } & \multicolumn{1}{c}{ RESULTADOS } \\
\hline Dimensão máxima característica (mm) & 19,00 \\
\hline Módulo de Finura & $4,39 \pm 0,05$ \\
\hline Umidade (\%) & $23,69 \pm 0,07$ \\
\hline
\end{tabular}

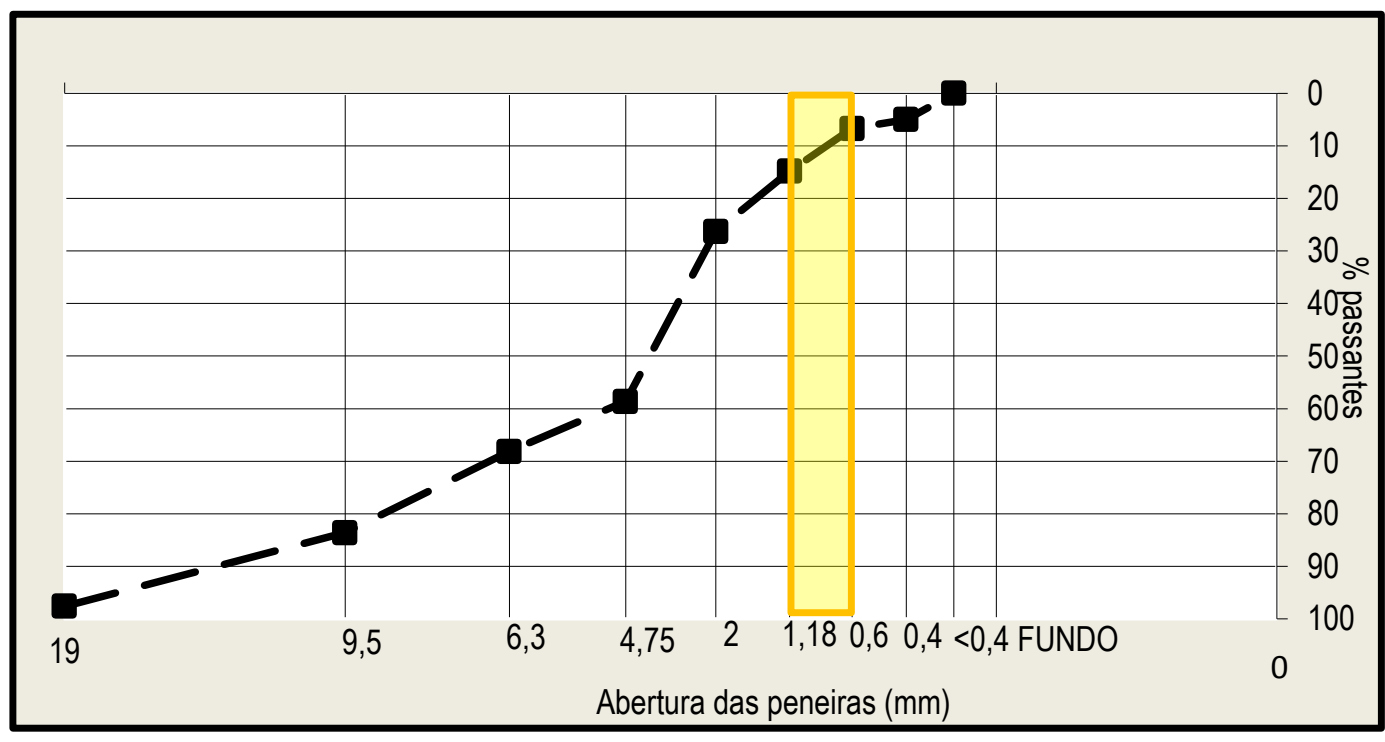

Figura 4: Curva granulométrica do resíduo, com destaque para a faixa utilizada.

Após a análise de todos os materiais utilizados nos procedimentos experimentais foram encontrados os índices de massa específica como mostrado na Tabela 5, exceção do cimento e da metacaulinita, onde os valores obtidos foram fornecidos pela Votorantim Cimentos e por MARQUES [22].

Tabela 5: Massas específicas ( $\rho$ ) dos materiais selecionados.

\begin{tabular}{l|l|l}
\hline MATERIAIS & $\rho\left(\mathbf{g} / \mathbf{c m}^{3}\right)$ & MÉTODO/FONTE \\
\hline Resíduos & $0,63 \pm 0,16$ & NBR 7190:1997 [20] \\
\hline Areia & $2,65 \pm 0,02$ & NBR 9776:1988 [31] \\
\hline CP IV - 32 & $2,94 \pm 0,01$ & Votorantim Cimentos \\
\hline Metacaulinita & $2,66 \pm 0,01$ & Picnometria a gás Hélio [22] \\
\hline $\mathrm{Ca}(\mathrm{OH})_{2}$ & $2,17 \pm 0,15$ & NBR NM 23:2001 [23] \\
\hline
\end{tabular}

A Figura 5 mostra o consumo de cimento para os compósitos estudados. Com a substituição de parte do cimento pela metacaulinita e $\mathrm{Ca}(\mathrm{OH})_{2}$ observa-se uma redução no consumo de cimento do traço $\mathrm{T} 1$ para $505 \mathrm{~kg} / \mathrm{m}^{3}$ na produção do traço T2. Considerando-se o compósito com maior teor de adição de resíduos (T4) a redução da massa de cimento por metro cúbico foi de aproximadamente $71 \mathrm{~kg}$, representando $15,27 \%$ a menos de cimento em relação a T1.

Observa-se que a redução gradativa do consumo de cimento por $\mathrm{m}^{3}$, para cada traço, deve-se ao aumento do volume de vazios pela adição dos resíduos, conforme apresentado mais adiante na Tabela 6. Como esperado, a adição dos resíduos reduziu a compactação do material.

Eliminando-se a massa dos resíduos (T5), mas mantendo-se a substituição de parte do cimento na especificação do traço, alcançou-se um índice de cerca de $0,5 \%$ a menos de cimento por metro cúbico de argamassa. 


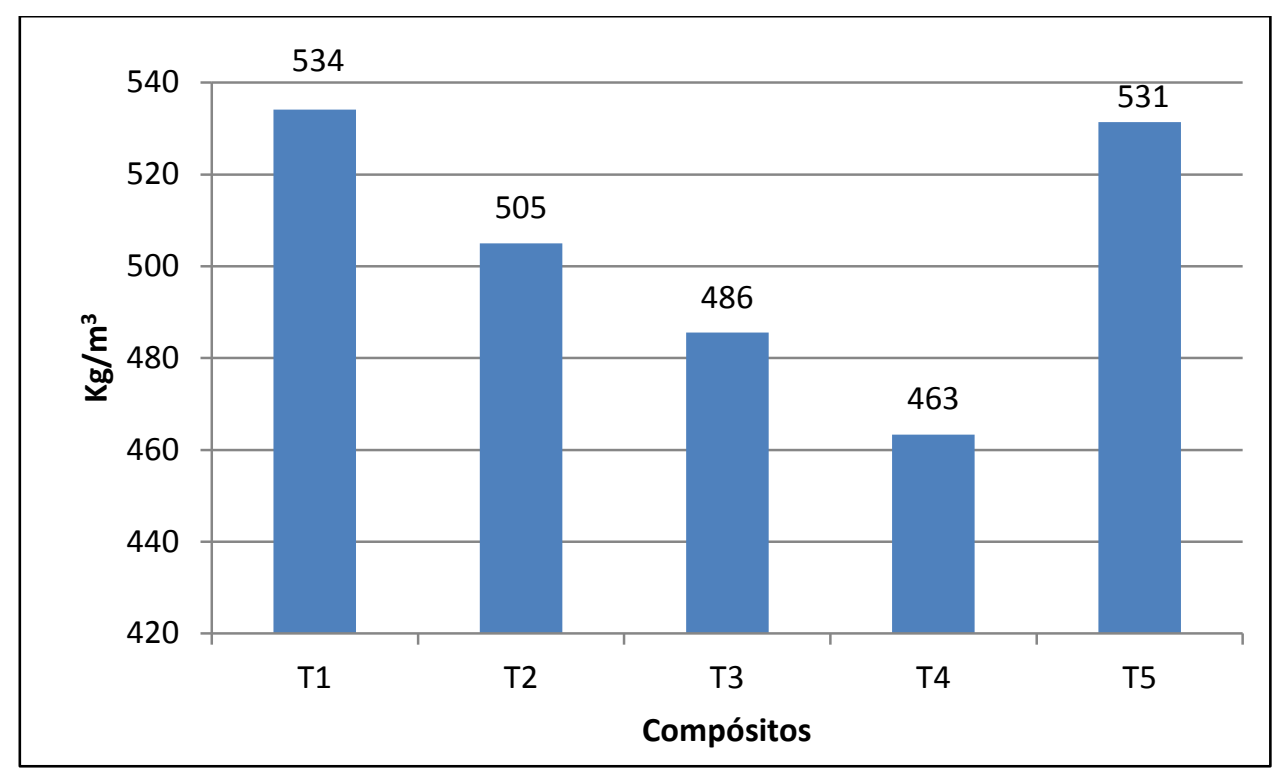

Figura 5: Consumo de cimento.

\subsection{Análise das características dos compósitos endurecidos}

Nas primeiras avaliações em relação à produção dos compósitos, durante o processo de mistura, observou-se que sem a utilização de um componente de compatibilização entre o cimento e o resíduo madeireiro seria inviável a sua confecção. Este fato foi observado, quando da moldagem dos painéis para a análise térmica, após 3 dias de idade dos primeiros painéis com 2,5\% de resíduos, não houve qualquer ganho de resistência, uma vez que a hidratação do cimento foi totalmente inibida (Figura 6), não sendo possível sequer removê-los do local, pois apresentaram características de desintegração ao menor esforço (esfarelamento).

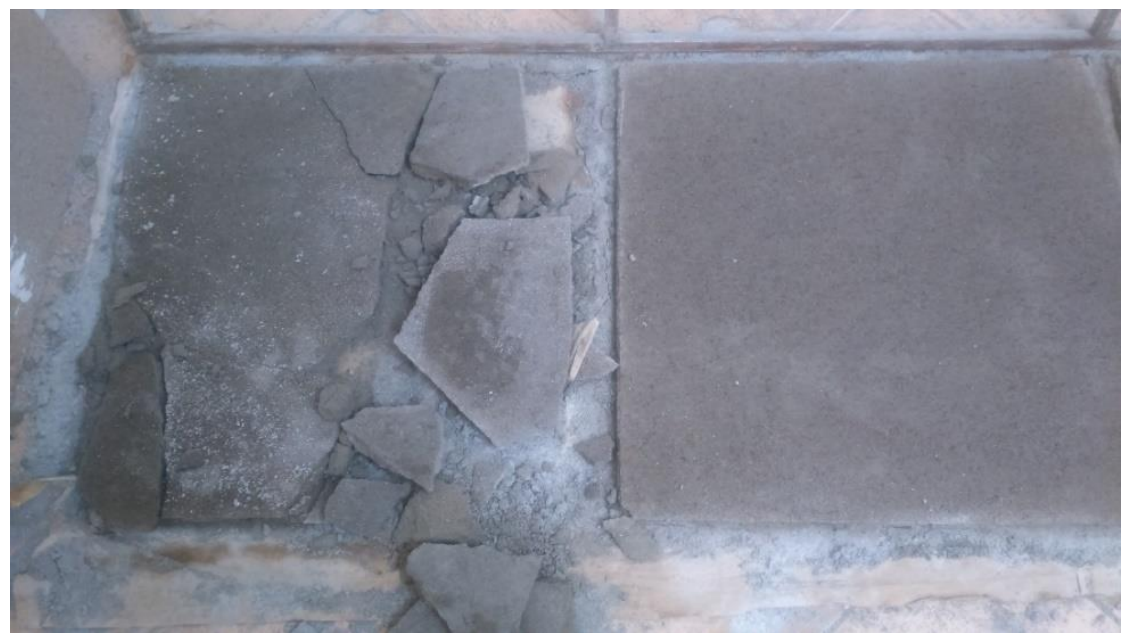

Figura 6: Painéis produzidos sem adição da metacaulinita e $\mathrm{Ca}(\mathrm{OH})_{2}$ : sem ganho de resistência em até 3 dias.

Na reformulação da composição do compósito pela adição da metacaulinita e do $\mathrm{Ca}(\mathrm{OH})_{2}$, foi possível, na mesma idade do compósito, manipulá-lo e removê-lo do local, sem oferecer danos físicos, pois estes já apresentavam ganhos de resistência aparente.

Finalmente, após estabelecimento dos traços definitivos, moldagem e ensaios, passou-se a análise dos índices físicos do compósito endurecido, chegando-se aos resultados mostrados na Tabela 6. 
Tabela 6: Características físicas dos compósitos endurecidos, determinados por imersão em água (médias e desvio padrão).

\begin{tabular}{l|c|c|c|c|c}
\hline \multirow{2}{*}{ ÍNDICES FÍSICOS } & \multicolumn{5}{c}{ COMPÓSITOS } \\
\cline { 2 - 6 } & $\mathbf{T 1}$ & T2 & T3 & T4 & T5 \\
\hline Taxa Absorção $\mathrm{H}_{2} \mathrm{O}(\%)$ & $11,42 \pm 0,44$ & $11,31 \pm 0,47$ & $14,08 \pm 1,78$ & $15,94 \pm 4,54$ & $7,86 \pm 0,32$ \\
\hline Volume Vazios $(\%)$ & $20,93 \pm 0,73$ & $21,28 \pm 2,63$ & $22,61 \pm 3,16$ & $24,49 \pm 5,01$ & $14,36 \pm 0,28$ \\
\hline $\begin{array}{l}\text { Massa específica da amostra seca }\left(\mathrm{g} / \mathrm{cm}^{3}\right) \\
\text { Massa específica da amostra saturada } \\
\left(\mathrm{g} / \mathrm{cm}^{3}\right)\end{array}$ & $1,832 \pm 0,01$ & $1,882 \pm 0,15$ & $1,607 \pm 0,02$ & $1,537 \pm 0,12$ & $1,826 \pm 0,109$ \\
\hline \begin{tabular}{l} 
Massa específica real $\left(\mathrm{g} / \mathrm{cm}^{3}\right)$ \\
\hline
\end{tabular} & $2,042 \pm 0,00$ & $2,095 \pm 0,18$ & $1,833 \pm 0,05$ & $1,781 \pm 0,07$ & $1,970 \pm 0,112$ \\
\hline
\end{tabular}

A taxa de absorção de água e o volume de vazios para os compósitos T1 e T2 não diferiram entre si em grau significativo. Isso mostra que a adição do pequeno teor de resíduos não interfere significativamente nesses itens. Já para os compósitos T3 e T4 apresentaram um aumento da taxa de absorção de água, porém o índice de vazios não apresentou uma variação na mesma proporção, embora também tenha sido registrado um aumento regular. O traço T5 apresentou uma queda significativa em absorção de água e em volume de vazios, certamente devido ao aumento da compacidade proporcionada pela metacaulinita e $\mathrm{Ca}(\mathrm{OH})_{2}$ e pela ausência do resíduo madeireiro.

LIMA[32] em testes de compósito cimentício com adição de resíduos madeireiros substituiu teores entre 20 e $100 \%$ do agregado miúdo. Nesses testes houve significativa influência dos resíduos nas características de redução da massa específica, aumento do volume de vazios e aumento da absorção de água, com índices de 29,37\%, 105,46\% e 188,18\%, respectivamente. Os testes mostraram maior sensibilidade para substituição de $100 \%$ do agregado por resíduos.

A menor massa específica da amostra seca foi obtida com a adição dos resíduos em maior teor (T4), que sofreu uma redução de cerca de $19 \%$ em relação ao traço de referência (T1). O compósito T2, embora tenha recebido um pequeno percentual do componente madeireiro, apresentou também pequeno aumento na massa específica da amostra seca, possivelmente causado pela adição do material fino (metacaulinita e $\left.\mathrm{Ca}(\mathrm{OH})_{2}\right)$. O traço T5, sem resíduos, manteve a massa específica compatível com a referência T1, embora, em relação a esta, tenha mostrado melhor desempenho em termos de compacidade (reduzido teor de vazios e de absorção de água).

\subsection{Análise do desempenho térmico}

As medições simultâneas efetuadas interna e externamente no dispositivo mostraram o desempenho térmico do material conforme Tabela 7, para o tempo limite de testes.

Tabela 7: Temperaturas médias e variação, no tempo máximo de aquecimento (30 min).

\begin{tabular}{|c|c|c|c|}
\hline PAINÉIS & $\begin{array}{c}\text { EXTERNA }\left({ }^{\circ} \mathrm{C}\right) \\
\text { TEMPO }=30\end{array}$ & $\begin{array}{c}\text { INTERNA }\left({ }^{\circ} \mathrm{C}\right) \\
\text { TEMPO }=30\end{array}$ & $\begin{array}{c}\text { COEFICIENTE DE } \\
\text { VARIAÇÃO (\%) }\end{array}$ \\
\hline $\mathrm{T} 1$ & $40,7 \pm 0,88$ & 59,0 & 18,4 \\
\hline $\mathrm{T} 2$ & $41,8 \pm 0,79$ & 61,7 & 19,3 \\
\hline $\mathrm{T} 3$ & $43,8 \pm 0,53$ & 63,6 & 17,8 \\
\hline $\mathrm{T} 4$ & $44,5 \pm 0,58$ & 63,4 & 18,2 \\
\hline
\end{tabular}

Para análise estatística da temperatura medida entre os ambientes interno e externo em cada teor de resíduos, utilizou-se a técnica de análise de variância (ANOVA), entre os traços (T1 a T4). Observou-se que as medidas de dispersão mostraram-se muito próximas entre si, indicando certa uniformidade na evolução das temperaturas para cada traço. Os coeficientes de variação mostram que o distanciamento das medições (interna $x$ externa) para as médias obtidas são similares. Finalmente, de acordo com o teste $F$, não foram encontradas evidências de diferenças significativas, ao nível de 5\% de probabilidade, entre as resistências térmicas dos painéis. Resulta que aceitamos a hipótese nula de que não existe diferença entre as médias de variação 
da temperatura entre os tratamentos após 30 minutos, com os teores de resíduos e dimensões de corpos de prova testados.

Observando-se os dados da Tabela 6 nota-se que, embora apresente menor densidade pela adição dos resíduos, o produto de compatibilidade cimento-madeira (metacaulinita $\left.+\mathrm{Ca}(\mathrm{OH})_{2}\right)$ tende a reduzir a resistência térmica para pequenos teores dos resíduos, agravado pela pouca espessura das placas.

Comparando-se estes resultados com a metodologia de ADRIAZOLA [26], naquele trabalho a autora pesquisou painéis com espessura média de $17 \mathrm{~mm}$ e massa específica de $1,35 \mathrm{~g} / \mathrm{cm}^{3}$, assinalando que uma maior massa específica favorece uma maior condutividade térmica do material. Assim, conseguiu uma variação entre as temperaturas interna e externa nos protótipos de cerca de 39\%, sendo que no presente estudo, alcançou-se o melhor resultado em $32,3 \%$ de variação entre temperaturas interna $x$ externa (T2).

Por outro lado, analisando isoladamente as placas de cimento-madeira como material sólido, homogêneo de camada única, e ainda, tomando-se como referência o prescrito na NBR 15220-2 [33], em especial os dados de condutividade térmica e massa específica aparente da placa de fibrocimento (cujas propriedades físicas mais se aproximam do cimento-madeira), é possível calcular a resistência térmica e transmitância para os painéis, utilizando as Equações 9 e 10:

$$
U=1 / R
$$

$$
R=e / \lambda
$$

Onde,

$U=$ Transmitância térmica $\left(\mathrm{W} / \mathrm{m}^{2} . \mathrm{K}\right)$

$R=$ Resistência térmica $(\mathrm{m} 2 . \mathrm{K}) / \mathrm{W}$

$e=$ espessura do painel (m)

$\lambda=$ Condutividade térmica $(\mathrm{W} /(\mathrm{m} . \mathrm{K}))$

Assim, considerando a espessura e $=0,015 \mathrm{~m}$ para os painéis em estudo e os valores de massa específica aparente (amostra seca), oriundos da Tabela 6, temos o desempenho térmico como mostrado na Tabela 8. Para a mesma espessura dos painéis a transmitância térmica é diretamente proporcional à massa específica do material. A maior transmitância térmica foi observada nos painéis com argamassa comum (T1).

Tabela 8: Desempenho térmico dos compósitos de referência e cimento-madeira.

\begin{tabular}{c|r|r|r|r}
\hline PAINÉIS & $\begin{array}{c}\text { MASSA ESPECífI- } \\
\text { CA }\left(\mathrm{kg} / \mathrm{m}^{3}\right)\end{array}$ & $\begin{array}{c}\lambda \\
(\mathrm{w} /(\mathrm{m} . \mathrm{k}))\end{array}$ & $\begin{array}{c}\text { RESISTÊNCIA } \\
\text { TÉRMICA } \\
\left(\left(\mathrm{m}^{2} \cdot \mathrm{k}\right) / \mathrm{w}\right)\end{array}$ & $\begin{array}{c}\text { TRANSMITÂNCIA } \\
\text { TÉRMICA } \\
\left(\mathrm{w} / \mathrm{m}^{2} \cdot \mathrm{k}\right)\end{array}$ \\
\hline $\mathrm{T} 1$ & 1832 & 1,15 & 0,013 & 76,92 \\
\hline $\mathrm{T} 2$ & 1882 & 0,65 & 0,023 & 43,34 \\
\hline $\mathrm{T} 3$ & 1607 & 0,65 & 0,023 & 43,34 \\
\hline $\mathrm{T} 4$ & 1537 & 0,65 & 0,023 & 43,34 \\
\hline
\end{tabular}

NOTA: o valor de $\lambda=0,65 \mathrm{~W} /(\mathrm{m} . \mathrm{K})$ (Condutividade térmica) é relativo à placa de fibrocimento ([29]), que situa-se na faixa para a massa específica dos compósitos cimento-madeira.

A resistência térmica, obtida por similaridade com o fibrocimento em termos de massa específica, mostrou-se maior que o material convencional (T1), mas ainda abaixo dos valores encontrados por ADRIAZOLA [26] para os painéis de cimento-madeira, que foi de $0,06 \mathrm{~m}^{2} . \mathrm{K} / \mathrm{W}$. A transmitância térmica resulta então, maior para o compósito T1 e menor para os compósitos cimento-madeira.

Os resíduos adicionados à argamassa convencional alteram a massa específica do compósito reduzindo-a e tendem a aumentar a resistência térmica. Isso implica em redução da condutividade e transmitância, como mostrado na Tabela 8, embora na montagem do dispositivo de testes o conjunto de painéis tenha, em geral, apresentado um mau desempenho.

\subsection{Análise da resistência à compressão}

Após obtenção dos dados foram computados os resultados dos ensaios, através da Equação (3). As médias de resistência à compressão são apresentadas na Tabela 9 . 
Tabela 9: Resultados dos ensaios de resistência à compressão. Médias com letras diferentes indicam diferença significativa entre si pelo teste Tukey a $5 \%$ de probabilidade.

\begin{tabular}{c|r}
\hline \multicolumn{2}{c}{ RESISTÊNCIA À COMPRESSÃO (MPA) } \\
\hline $\mathrm{T} 1$ & $17,06 \pm 1,79 \mathrm{a}$ \\
\hline $\mathrm{T} 2$ & $14,51 \pm 2,47 \mathrm{~b}$ \\
\hline $\mathrm{T} 3$ & $9,35 \pm 2,06 \mathrm{c}$ \\
\hline $\mathrm{T} 4$ & $6,81 \pm 1,27 \mathrm{~d}$ \\
\hline $\mathrm{T} 5$ & $20,41 \pm 1,63 \mathrm{e}$ \\
\hline
\end{tabular}

A ANOVA para a resistência à compressão mostrou diferença significativa entre os compósitos $\left(F_{0,05}\right.$ $=86,3$; valor $-p<0,05)$. Os compósitos $\mathrm{T} 2$ a T4, quando comparado com $\mathrm{T} 1$ apresentaram diferenças significativas em decréscimo de resistência (comprovado pelo teste Tukey a 5\% de probabilidade). Já o compósito T5 também diferiu de T1, mas com acréscimo de resistência, mostrando que a adição dos resíduos nos compósitos T2-T4 faz cair o desempenho mecânico.

Para o menor teor de adição dos resíduos (T2) a diminuição da resistência, em relação à referência (T1) é pequena, com variação de cerca de $-17 \%$. A resistência tende a diminuir para os demais teores testados, chegando a -60\% para o compósito T4 (com 7,5\% de resíduos).

Além das aplicações térmicas e acústicas outras podem ser beneficiadas pelas propriedades de menores densidade e resistência - como sugerido por GONG et al [34], onde testes de dissipação de energia por impacto em elementos de cimento-madeira, com $35 \mathrm{~mm}$ de espessura, reduziu a força máxima de desaceleração em $72 \%$, amortecendo melhor os impactos, quando comparado com o concreto. Os resultados também estão próximos aos obtidos em pesquisas anteriores que alcançaram valores de resistência à compressão na faixa de 3,6 a 6,9 $\mathrm{MPa}$ [11], com possibilidade de aplicação em controle acústico e em revestimentos internos de paredes e tetos, por suas propriedades de baixa densidade [35].

No compósito T5, com o mesmo teor de metacaulinita e $\mathrm{Ca}(\mathrm{OH})_{2}$, porém sem adição dos resíduos, a resistência foi incrementada em comparação com T1, em cerca de 20\%, demonstrando o benefício da reação pozolânica e do efeito de preenchimento de vazios para o aumento de resistência.

\subsection{Análise da resistência à flexão a 4 pontos}

Os resultados dos testes da resistência à flexão a quatro pontos são apresentados na Tabela 10. Estes valores são compatíveis com aqueles encontrados com placas de gesso revestido com papel (acartonado), apresentados por TITTELEIN [9]. Naqueles testes as placas tinham espessuras iguais às deste estudo, porém com razão cimento/madeira muito maior $(0,5)$, indicando um bom desempenho para o compósito cimento-madeira.

Tabela 10: Valores de MOR e MOE para ensaio de flexão a 4 pontos.

\begin{tabular}{c|c|c}
\hline & MOR (MPa) & MOE (GPa) \\
\hline MÉDIA & $2,18 \pm 0,52$ & $8,37 \pm 1,64$ \\
\hline
\end{tabular}

Os ensaios de flexão foram realizados apenas para o compósito T2, devido ao seu melhor desempenho nos testes de resistência à compressão. Depois da execução dos ensaios sobre 10 corpos de prova em forma de chapas prismáticas retangulares, houve inconsistência em um deles, sendo o espécime com resultado inválido eliminado do conjunto. Os valores obtidos neste trabalho são próximos, para painéis similares em ensaio de flexão, aos obtidos por LIMA et al [13] que obteve 1,95 MPa para o MOR e KARADE [36] que apresentou estudos com índices de MOE variando entre 2,86 e 6,66 GPa.

Material com essas características tem aplicação indicada para proteção térmica aplicando-se em revestimento de paredes, com desempenho superior quando comparado com o uso de placas de gesso, isto devido à maior compacidade das placas de gesso em relação ao cimento-madeira (TITTELEIN [9]).

\section{CONCLUSÕES}

Este trabalho procurou analisar as propriedades físicas, térmicas e mecânicas de compósitos cimento-madeira, com teores de resíduos entre $0 \%$ a 7,5\% e modificação do aglomerante através da adição de metacaulinita (10\%) e Hidróxido de Cálcio (5\%). 
A modificação do aglomerante reduziu o consumo do cimento Portland, com consequente redução das emissões de $\mathrm{CO}_{2}$ devidas ao processo de fabricação, principalmente porque a emissão durante o processo de fabricação da metacaulinita é menor. Além disso, esta substituição forneceu maior compacidade ao compósito endurecido, diminuindo os vazios e melhorando a resistência à compressão e flexão.

A substituição de até 7,5 \% do agregado miúdo por resíduos de madeira proporcionou uma redução na massa específica do compósito, chegando a $19 \%$ a menos em relação ao material convencional, porém, ocasionou uma substancial redução na resistência a compressão (-60\%). A influência dos resíduos no desempenho mecânico ficou comprovada quando se analisou o compósito sem os resíduos (T5), que apresentou ganho de resistência à compressão em $20 \%$.

Quanto ao desempenho térmico, na configuração dos dispositivos apresentada, não foram encontradas evidências de diferenças significativas, ao nível de 5\% de probabilidade, entre as resistências térmicas dos painéis. Dessa forma, aceitou-se a hipótese de igualdade estatística entre as médias de isolamento térmico entre os painéis após 30 minutos, com os teores de resíduos e dimensões de corpos de prova testados. Porém, analisando isoladamente o material sólido, percebe-se a tendência à redução da transmitânica térmica através dos painéis cimento-madeira em relação ao material convencional.

Para trabalhos futuros sugere-se desenvolver ensaios com maiores teores de resíduos e maiores espessuras dos painéis cimento-madeira, bem como desenvolvimento de paredes duplas, com ou sem material de preenchimento, dando a devida atenção à compatibilidade entre os materiais convencionais e alternativos.

\section{AGRADECIMENTOS}

Os autores agradecem à Universidade Federal do Amazonas (UFAM), Laboratório de Ensaios Mecânicos; à Faculdade de Rondônia (FARO), laboratório de materiais; ao prof. Alejandro A. H. Gallardo (FARO); à Votorantim Cimentos - Porto Velho, laboratórios de ensaios tecnológicos.

\section{BIBLIOGRAFIA}

[1] KRIZOVA, K., HELA, R., "Use of Green cement in concrete for friendly building construction", In: Latest Trends in Sustainable and Green Development, pp. 17-21, Barcelona, Spain, oct. 2012.

[2] SOUZA, T. C., SUZUKI, S., LUDVIG, P., et al., "Nanotubos de carbono: Um caminho para a sustentabilidade de materiais cimentícios”, Concreto e Construções, v. 1, n. 77, pp. 20-24, jan-mar. 2015.

[3] MARCHESAN, R. Rendimento e Qualidade de Madeira Serrada de Três Espécies Tropicais. Dissertação M.Sc., Setor de Ciências Agrárias, Universidade Federal do Paraná, Curitiba, PR, 2012.

[4] NA, B., ZHIQIANG W., HAIQIN W., et al., "Wood-cement compatibility review”, Wood Research, v. 59, n. 5, pp. 813-825, jan. 2014.

[5] FAN, M., NDIKONTARB, M. K., ZHOUA, X., et al., "Cement-bonded composites made from tropical woods: Compatibility of wood and cement”, Construction and Building Materials, v. 36, pp. 135-140, jun. 2012.

[6] KARADE, S. R., AGGARWAL, L. K. "Cement-bonded lignocellulosic composites for building applications”, Metals Materials and Processes, v. 17, n. 2, pp. 129-140, dec. 2005.

[7] CASTRO, V., ARAÚJO, R. D., PARCHEN, C. et al. "Avaliação dos efeitos de pré-tratamentos da madeira de eucalyptus benthamii maiden \& cambage no grau de compatibilidade com cimento Portland", Revista Árvore, v.38, n.5, pp.935-942, jul. 2014.

[8] MACÊDO, A. N., SOUZA, A. A. C., POMPEU NETO, B.B. "Chapas de cimento-madeira com resíduos da indústria madeireira da Região Amazônica”, Ambiente Construído, v. 12, n. 2, pp. 131-150, jun. 2012.

[9] TITTELEIN, P., CLOUTIER, A., BENOÎT, B. "Design of a low-density wood-cement particleboard for interior wall finish”, Cement and Concrete Composites, v. 34, n. 2, pp. 218-222, oct. 2011.

[10] MEDINA, E. A. Pozolanicidade do metacaulim em sistemas binários com cimento Portland e hidróxido de cálcio, Dissertação de M.Sc. - Escola Politécnica, Universidade de São Paulo, São Paulo, SP, Brasil, 2011.

[11] RONQUIM, R., FERRO, F. S., ICIMOTO, F. H., et al., "Physical and Mechanical Properties of WoodCement Composite with Lignocellulosic Grading Waste Variation", International Journal of Composite Materials, v. 4, n. 2, pp. 69-72, 2014.

[12] FADAI, A., WINTER, W., GRUBER, M. "Wood based construction for multi-storey buildings. the potential of cement bonded wood composites as structural sandwich panels", In: World Conference in Timber Engineering, pp. 125-133, Auckland, New Zealand, jul. 2012. 
[13] LIMA, A. J. M., IWAKIRI, S., LOMELI-RAMÍREZ, M. G. "Study of the interaction of portland cement and pinus wood for composites using bragg sensors in optical fibers", Bioresources. v. $10 \mathrm{n} .4$, pp. 6690-6704. 2015.

[14] ABNT - ASSOCIAÇÃO BRASILEIRA DE NORMAS TÉCNICAS. NBR 5736: Cimento Portland Pozolânico. Rio de Janeiro ABNT, 1991. 5p.

[15] ABNT - ASSOCIAÇÃO BRASILEIRA DE NORMAS TÉCNICAS. NBR 11579: Cimento PortlandDeterminação do índice de finura por meio da peneira $75 \mu m$ ( $\left.n^{\circ} 200\right)$. Rio de Janeiro ABNT, 2012. 4p.

[16] ABNT - ASSOCIAÇÃO BRASILEIRA DE NORMAS TÉCNICAS. NBR NM 65: Cimento Portland Determinação do tempo de pega. Rio de Janeiro ABNT, 2003. 4p.

[17] ABNT - ASSOCIAÇÃO BRASILEIRA DE NORMAS TÉCNICAS. NBR 10007: Amostragem de resíduos sólidos. Rio de Janeiro ABNT, 2004. 21p.

[18] ABNT - ASSOCIAÇÃO BRASILEIRA DE NORMAS TÉCNICAS. NBR 7217: Agregados-Determinação da composição granulométrica. Rio de Janeiro ABNT, 1987. 3p.

[19] ABNT - ASSOCIAÇÃO BRASILEIRA DE NORMAS TÉCNICAS. NBR 7211: Agregados para concreto - Especificação. Rio de Janeiro ABNT, 2009. 9p.

[20] ABNT - ASSOCIAÇÃO BRASILEIRA DE NORMAS TÉCNICAS. NBR 7190: Projeto de estruturas de madeira. Rio de Janeiro ABNT, 1997. 107p.

[21] MT - DEPARTAMENTO NACIONAL DE ESTRADAS DE RODAGEM. DNER-ME 080: Solos análise granulométrica por peneiramento. Rio de Janeiro, DNER-ME, 1994. 4p.

[22] MARQUES, M. G. S. Estudo das propriedades físicas e mecânicas e da durabilidade de compósitos cimentícios reforçados com fibra amazônica. Tese de D.Sc., Escola de Engenharia de São Carlos, Universidade de São Paulo, São Carlos, SP, Brasil, 2015.

[23] ABNT - ASSOCIAÇÃO BRASILEIRA DE NORMAS TÉCNICAS. NBR NM 23: Cimento portland e outros materiais em pó - Determinação da massa específica. Rio de Janeiro ABNT, 2001. 5p.

[24] BASF SA. Linha MasterPolyheed®: Aditivo plastificante polifuncional - Ficha Técnica. https://assets.master-builders-

solutions.basf.com/Shared\%20Documents/PDF/Portuguese\%20(Brazil)/Ficha_Tecnica_MasterPolyheed.pdf. Acessado em julho de 2017.

[25] ABNT - ASSOCIAÇÃO BRASILEIRA DE NORMAS TÉCNICAS. NBR 7215: Cimento PortlandDeterminação da resistência à compressão. Rio de Janeiro: ABNT, 1996, 8p.

[26] ADRIAZOLA, M. K. O. Avaliação Experimental por meio de protótipos e por simulação de painéis de madeira para habitação de interesse social. Tese de D.Sc., Universidade Federal do Paraná, Curitiba, PR, Brasil, 2008.

[27] ABNT - ASSOCIAÇÃO BRASILEIRA DE NORMAS TÉCNICAS. NBR 15575-4: Edificações habitacionais - Desempenho Parte 4: Sistemas de vedações verticais internas e externas. Rio de Janeiro ABNT, 2013. 5p.

[28] ABNT - ASSOCIAÇÃO BRASILEIRA DE NORMAS TÉCNICAS. NBR 5739: Argamassas e concretos endurecidos - Concreto - Ensaios de compressão de corpos de prova cilíndricos. Rio de Janeiro ABNT, 2007. $9 \mathrm{p}$.

[29] ABNT - ASSOCIAÇÃO BRASILEIRA DE NORMAS TÉCNICAS. NBR 12142: Concreto - Determinação da resistência à tração na flexão de corpos de prova prismáticos. Rio de Janeiro ABNT, 2010. 5p.

[30] ABNT - ASSOCIAÇÃO BRASILEIRA DE NORMAS TÉCNICAS. NBR 9778: Argamassas e concretos endurecidos - Determinação da absorção de água, índice de vazios e massa específica. Rio de Janeiro ABNT, 2006. 4p.

[31] ABNT - ASSOCIAÇÃO BRASILEIRA DE NORMAS TÉCNICAS. NBR 9776: Agregados - Determinação da massa específica de agregados miúdos por meio do frasco Chapman. Rio de Janeiro ABNT, 1988. $3 \mathrm{p}$.

[32] LIMA, A. J. M., IWAKIRI, S. "Utilização de resíduos da madeira de pinus spp. como substituição ao agregado miúdo na produção de blocos de concreto para alvenaria estrutura", Ciência Florestal, v. 24, n. 1, pp. 223-235, jan.-mar. 2014. 
[33] ABNT - ASSOCIAÇÃO BRASILEIRA DE NORMAS TÉCNICAS. NBR 15220-2: Desempenho térmico de edificações Parte 2: Método de cálculo da transmitância térmica, da capacidade térmica, do atraso térmico e do fator solar de elementos e componentes de edificações. Rio de Janeiro ABNT, 2005. 34p.

[34] GONG, A., HARICHANDRAN, Ronald S. "Wood-Cement Particleboard: Impact Behavior and Potential Application in Crash Barriers", Journal of Materials in Civil Engineering. n. 24, pp. 134-140, jan. 2012.

[35] CAI, Z., ROSS, R. J., "Wood Based composites and panel products”. In: Forest Products Laboratory.

Wood Handbook -Wood as an engineering material. Centennial edition, Chapter 12 Mechanical Properties of Wood-Based Composite Materials, Madison, WI - USA, USDA, 2010.

[36] KARADE, S. R. "Cement-bonded composites from lignocellulosic wastes", Construction and Building Materials. n. 24, pp. 1323-1330, feb. 2010. 